\title{
MEDIAÇÃO JUDICIAL DE CONFLITOS \\ - UM ESTUDO DE CASO SOBRE DESAFIOS INSTITUCIONAIS
}

\section{Bárbara Silva Diniz}

Mestre em Direitos Humanos e Cidadania pela Universidade de Brasília; especialista em Direito Civil pela Fundação Getúlio Vargas; advogada, mediadora de conflitos. Atualmente é pesquisadora do Núcleo de Estudos para a Paz e os Direitos Humanos (NEP) do Centro de Estudos Avançados Interdisciplinares da Universidade de Brasília, participante do projeto de extensão e ação contínua "Estudar em Paz: mediação de conflitos no contexto escolar" e membro do grupo de pesquisa "Direitos Humanos, educação, mediação e movimentos sociais". barbaradiniz3@gmail.com

\section{Resumo}

A mediação de conflitos está institucionalizada no ordenamento jurídico brasileiro. Prevista em diversos leis e integrando políticas públicas diversas, atualmente seu maior risco pode ser 0 de ser considerada uma "panaceia universal", ideal para todos os tipos de conflitos, o que, ao final, contribuiria para sua fragilização e descaracterização. Considerando essa problemática, o presente artigo tem como objetivo analisar o primeiro caso de mediação judicial do Distrito Federal, verificando lições que ele pode trazer ao momento atual e contribuindo para uma reflexão sobre os desafios da mediação judicial de conflitos na atualidade.

\section{Palavras-chaves:}

Mediação de conflitos. Mediação judicial. Conflito. Lide.

\section{JUDICIAL CONFLICTS MEDIATION - A CASE STUDY ON INSTITUTIONAL CHALLENGES}

\section{Abstract:}

Conflicts mediation is institutionalized in the Brazilian legal system. Provided in laws and integrating public policies, currently its biggest risk may be to be considered a "universal panacea", ideal for all types of conflicts, which, ultimately, would contribute to their brittleness and mischaracterization. Considering that, this article aims to analyse the Federal District first case of judicial conflicts mediation, examining lessons it can bring to the present moment and contributing to a reflection on the challenges of judicial conflict mediation nowadays. 


\section{Keywords:}

Conflict mediation. Judicial mediation. Conflict. Adjudication.

\section{Sumário}

1 Introdução. 2 A mediação de conflitos. 3 A mediação de conflitos no TJDFT. 40 conflito. 5 Argumentações e estratégia. 6 Do processo de mediação e da decisão. 7 Análise e discussão. 8 À guisa de conclusão? 9 Referências. 


\section{INTRODUÇÃO}

Abrir um artigo não é fácil. Pensar no que escrever, despertando o interesse sem muito revelar sempre me pareceu assustador. Por isso mesmo, já tomo a liberdade de utilizar-me da primeira pessoa. Sei que é uma ação não hegemônica diante da práxis acadêmica, principalmente jurídica, de escrever em terceira. Contudo, "escrever não está somente em colocar palavras e símbolos num papel". Na verdade, o escritor expóe no escrito suas realidades ou fantasias, mostrando que a vida se dá entre lembranças e esquecimentos (ADAD, 2015, p. 19).

Discorro disso porque lembranças e esquecimentos fazem parte deste trabalho, pois ele trata do primeiro caso de mediaçáo de conflitos judicial no Distrito Federal, ocorrido em 2002. Quanto a isso, esclareço que, aqui, uso indistintamente os termos mediação e mediação de conflitos como sinônimos.

O caso chegou a mim por meio do desenvolvimento de uma pesquisa sobre a mediação judicial, não publicada. Em razão do sigilo tradicional, não tive acesso aos documentos do procedimento em si nem ao teor das discussóes nas sessôes. A análise deu-se nos processos judiciais a ele relacionados. Isso também significa que não realizei diligências junto às partes, pois meus objetivos foram verificar como a mediação foi vista e tratada por elas, seus advogados e os magistrados da época. Assim, as estratégias utilizadas e a forma como os processos judiciais e o de mediação de conflitos se desenvolveram é que são centrais.

De lá para cá a mediação de conflitos, de iniciativa experimental, efetivou-se como uma política pública. Assim, por exemplo, o Plano Nacional de Direitos Humanos (PNDH-3) relacionou-a a ações de acesso à Justiça, de prevenção de violências e de promoção de um sistema de justiça efetivo (BRASIL, 2010b). A Resolução no 125, de 29 de novembro de 2010, do Conselho Nacional de Justiça (CNJ), instituiu a política de tratamento adequado de conflitos no âmbito do Poder Judiciário. O Código de Processo Civil (CPC), Lei no 13.105, de 16 de março de 2015, determinou como prioridade a soluçáo consensual de conflitos, pela mediação ou pela conciliação (BRASIL, 2015b) ao passo que a Lei no 13.140, "Lei de Mediação", de 26 de maio de 2015, dispôs sobre a mediação extrajudicial e a autocomposição junto à Administração Pública (BRASIL, 2015a). Tudo isso sem falar na mediação comunitária (DISTRITO FEDERAL, 2012). 
Isso faz parecer que, no Brasil de hoje, vive-se o momento que a França viveu nos anos 90, denominada por Six (2001) de "a década da mediação". Nesse período houve sua institucionalização em todos os âmbitos da vida bem como o surgimento de uma expectativa irreal acerca dos benefícios que ela poderia trazer. Tornou-se comum considerá-la uma "panaceia universal" para todos os males sociais, fazendo surgir problemas que concorreriam para sua descaracterização e, até mesmo, seu questionamento. Diante disso, preocupa-me que esse possa ser o risco que o Brasil corre na atualidade.

Isso porque, assim como os demais métodos, a mediação de conflitos é aplicável a certos conflitos, mas pode ser ineficaz a outros. Quanto a isso, Fiss (2004), por exemplo, afirma que o problema dos defensores de métodos extrajudiciais é considerar que todos os conflitos possam ser igualmente tratados. Costa (2004), por sua vez, ao analisar a crise do processo judicial, que teria despertado o interesse por tais métodos, considera que esse interesse teria surgido porque os conflitos, qualquer que fosse sua natureza, passaram a ser resolvidos apenas pelo Poder Judiciário. Com isso, o que é visto como uma limitação ou um problema do sistema seria, na realidade, uma característica inerente a sua própria estrutura.

Considerando esses pontos, a forma de institucionalização da mediação, no Brasil, pode trazer, no futuro, sua própria crise. Assim, refletir sobre que desafios tal instituto enfrenta para sua consolidaçáo é o objetivo deste artigo. Para tanto, trago o primeiro caso de mediação judicial do Distrito Federal, analisando o que ele ainda poderia trazer ao momento atual.

Para melhor sistematização, além desta introdução, discorro sobre a mediação de conflitos em geral. Em seguida, apresento como funcionava, à época do caso, a área de mediação de conflitos do Tribunal de Justiça do Distrito Federal e dos Territórios (TJDFT). Na sequência, apresento o caso, analisando as estratégias utilizadas e a efetividade do processo, buscando liçóes que possam ainda nos ser úteis na atualidade.

Faço uso de pseudônimos para manter preservadas as identidades das pessoas envolvidas. Por essa mesma razão, também não indiquei o número dos processos, a maioria arquivada há muitos anos, nem fiz referências às páginas. 
Náo tenho pretensóes de que isto se torne uma análise definitiva. Até porque é possível que, do caso, surjam mais perguntas que respostas. O que eu busco, na verdade, é levantar questóes que possam servir de baliza para futuros estudos ou pesquisas com fins de continuação da discussão e para melhoria do instituto.

\section{A MEDIAÇÃO DE CONFLITOS}

Depois de tantos anos, parece-me, às vezes, que tudo já foi dito sobre mediação de conflitos. Outras vezes, apego-me à perspectiva de que os olhares são diferenciados, daí a necessidade de discorrer, mais uma vez, sobre ela. Assim, algumas das questôes que despertam o debate são a essência, o conceito e as concepçôes acerca do instituto. De fato, se no Brasil existe há muito uma discussão sobre isso, essa não é uma prerrogativa nossa. $\mathrm{Na}$ realidade, em todos os países aos quais chegou, a mediação despertou conflitos sobre tais temas.

Tanto é assim que, nos Estados Unidos houve, ainda nos idos de 1970, discussões sobre se a essência da mediação de conflitos seriam os interesses ou sua capacidade transformadora (BUSH; FOLGER, 2005). No mesmo período também surgiram debates sobre quais os melhores modelos de mediação comunitária: centrado na diminuição de processos judiciais e de discussōes entre vizinhos ou com foco na efetivaçấo de direitos civis e no fortalecimento comunitário (McGILLIS, 1997; BRADLEY; SMITH, 2000). Nos anos 90 foi a vez do debate sobre se o mediador poderia ser mais avaliativo e diretivo, expresso por Riskin (2002), ou deveria ser mais dialógico, defendido por Love e Kovack (2004).

Em relação ao Brasil, há também divergências que respingaram nas leis atuais. Assim, por exemplo, o $\mathrm{CPC}$, embora náo apresente um conceito do instituto, permite sua construção a partir do que está expresso no parágrafo $3^{\circ}$ do artigo 165, que diz:

$\$ 3^{\circ} \mathrm{O}$ mediador, que atuará preferencial mente nos casos em que houver vínculo anterior entre as partes, auxiliará aos interessados a compreender as questōes e os interesses em conflito, de modo que eles possam, pelo restabelecimento da comunicação, identificar, por si próprios, soluçôes consensuais que gerem benefícios mútuos (BRASIL, 2015b). 
Nessa concepção, a mediação de conflitos é um processo direcionado a pessoas em relaçóes contínuas de longa duração, que envolvem valores, sentimentos e interesses e açôes comprometidas. Santos (1988) chama a isso de relações de vínculo múltiplo ou multiplexas. Nelas, a forma de se lidar com o conflito torna a lide mais complexa, pois impede um distanciamento das partes diante das emoçóes existentes.

Ainda dentro dessa perspectiva, a mediação de conflitos não busca apenas o acordo em si e o fim da lide, mas, antes, restabelecer a comunicação, auxiliar as pessoas a compreender seus interesses e sentimentos e, a partir disso, permitir que elas tomem suas próprias decisóes, pensando prospectivamente sobre como manter a relação ou como lidar com conflitos futuros. Para tanto, o mediador não sugere nem avalia ou induz as partes a um acordo. Ao contrário, ele apenas colabora no desenvolvimento do diálogo.

Essa percepção é sutilmente diferente do que define a Lei da Mediação que, no parágrafo único de seu artigo $1^{\circ}$ conceitua o instituto como sendo: “[...] a atividade técnica exercida por terceiro imparcial sem poder decisório, que, escolhido ou aceito pelas partes, as auxilia e estimula a identificar ou desenvolver soluçóes consensuais para a controvérsia” (BRASIL, 2015a).

Apesar do terceiro mencionado (o mediador) não possuir poder decisório, ele pode estimular as partes a tomarem suas próprias decisóes. Nesse sentido, ele pode atuar de forma mais diretiva, como defende Riskin (2002), distanciando-se da postura prevista no CPC, mais focado no estabelecimento de laços e mais próximo do defendido por Love e Kovack (2004). Como ambas as leis são recentes, o debate está longe de se encerrar e será a doutrina a analisar os posicionamentos.

Nesse sentido, do lado doutrinário, Sales (2003, p. 40) considera a mediação uma autocomposição assistida, ou seja, um processo "pelo qual [um terceiro] facilita a comunicação entre as partes, almejando a solução e a prevenção de conflitos". Para Calmon (2007, p. 119), trata-se da "intervenção de um terceiro imparcial e neutro, sem qualquer poder de decisão, para ajudar os envolvidos em um conflito a alcançar voluntariamente uma solução mutuamente aceitável”. Serpa (1997, p. 105), por sua vez, conceitua a mediação como: 
[...] processo informal, voluntário, onde (sic) um terceiro interventor, neutro, assiste aos disputantes na resolução de suas questóes. O papel do interventor é ajudar na comunicação através de neutralização de emoçôes, formação de opçôes e negociação de acordos. Como agente fora do contexto conflituoso funciona como um catalisador de disputas, ao conduzir as partes às suas soluçóes, sem propriamente interferir na substância destas.

Dessa forma, discussóes sobre o conceito de mediação de conflitos perpassa as ideologias presentes sobre o instituto, ou seja, as formas de vê-lo e de percebê-lo. Tradicionamente, vistas como de três tipos: tradicional linear, transformadora e circular-narrativa.

A primeira, também conhecida como mediação de Harvard, focada em interesses ou voltada à resolução de problemas, vê a mediação de conflitos como uma negociação assistida, com o fim de evitar ou eliminar impasses para se alcançar um acordo satisfatório. $\mathrm{O}$ mediador, que atua num processo linear com etapas preestabelecidas, objetiva ajudar as partes a chegar ao acordo e, para tanto, pode ter uma atuaçáo tanto facilitadora, náo diretiva, quanto avaliativa ou restrita (RISKIN, 2002; COSTA, 2004).

Já o modelo transformativo ou mediação transformadora ${ }^{1}$ surgiu a partir das experiências voltadas ao desenvolvimento de direitos civis e políticos e para o fortalecimento de comunidades (BUSH; FOLGER, 2005). Nele, o acordo não é um objetivo, e sim apenas uma das diversas possibilidades, pois o que se busca é a transformação positiva da relação, a manutenção ou a restauração dos laços (SIX, 2001). Warat (2004) vai considerar que se prescinde completamente do acordo. Nesse modelo, diferencia-se mediação e conciliação, sendo essa centrada no acordo, e aquela o modelo focado nas pessoas ou no conflito.

Por fim, o modelo circular-narrativo, criado por Sara Cobb (1994), procura unir os dois modelos anteriores, focando tanto no conflito quanto no acordo. Parte da ideia de que as pessoas, o conflito e suas histórias náo podem ser vistos

1 O termo original é "transformative mediation", traduzido para o português como "mediação transformativa". Contudo no nosso léxico a expressão mais adequada seria "transformadora". O termo "transformativa" permaneceu pelo costume. Neste trabalho faço a opção pela tradução "transformadora”. 
isoladamente, e sim inter-relacionados a um todo maior. Costa (2004), com quem compartilho a percepção, considera, contudo, que ele é uma variante do modelo transformador, por ter foco na compreensão do conflito e não no acordo em si.

Dessa forma, ideologicamente, há dois modelos principais. De um lado, um que considera a mediação de conflitos um processo autocompositivo direcionado à busca de um acordo, podendo o mediador, para tanto, atuar ativamente. De outro, uma postura vinculada ao restabelecimento de laços e à conscientização de sentimentos.

Em qualquer situação, parece haver um consenso de que a mediação de conflitos é uma prática milenar (BARBOSA, 2007; MOORE, 1998), de forma que não me causou surpresa identificá-la também na obra de Pierre Clastres (2004, p. 103-104) sobre os índios Guayaki do Paraguai, em que o chefe indígena não é o que decide, mas o que busca uma conciliaçáo, em caso de conflitos, em nome da coesão do grupo.

Da mesma forma, se pensarmos que a União Soviética já possuía, em 1964, anos de experiência na mediação judicial e extrajudicial, e que a China, em 1919, já contava com os comitês de mediação popular (COHÉN, 1966), não causa surpresa Moore informar (1998) que o Federal Mediation and Conciliation Service surgiu em 1947 para mediar conflitos no setor industrial norte-americano.

No Brasil, as primeiras experiências parecem ter surgido com a mediação familiar interdisciplinar e em trabalhos relacionados à violência doméstica (MUSZKAT, 2005; BARBOSA, 2007), no início dos anos 90. No entanto, cabe mencionar que já há indicativo da existência de experiências ainda nos anos de 1970 (BRASIL, 2005).

Se formos considerar a legislaçáo, a primeira vez que surge a expressão “mediaçáa” foi em 1995, com o Decreto no 1.572, de 28 de julho do referido ano, que regulamentou a mediação de conflitos no âmbito das negociaçốes coletivas trabalhistas.

Mais tarde, a Lei ${ }^{\circ} 10.101$, de 19 de dezembro de 2000, permitiu a mediação em caso de impasse nas negociaçôes referentes à participação de trabalhadores nos lucros ou resultados das empresas (BRASIL, 1995; 2000).

Se formos considerar, no entanto, a linha teórica que admite como sinônimos "mediação" e "conciliação", é possível retroceder às Ordenaçôes do Reino, de 1480, que já previam a conciliação em processos cíveis. Posteriormente, no século 
18, os juízes de paz, leigos eleitos popularmente, tinham a função de promover a conciliação em processos cíveis e criminais antes das decisóes dos juízes de direito, nomeados pelo Imperador. $\mathrm{Na}$ área comercial, desde o século 19, o Código Commercial, de 1850, previa a conciliação obrigatória antes do processo judicial (MARTINS FILHO, 1999).

Tudo isso sem falar nos códigos de processo civil ou criminal, que sempre previram alguma possibilidade de conciliação, seja em audiência presidida pelo juiz, seja por meio de autocomposição direta das partes, bem como na instituição dos juizados especiais cíveis, com a Lei no 9.099, de 26 de setembro de 1995, que estabeleceu a conciliação como paradigma de atuação (BRASIL, 1995b).

Dessa forma, é possível perceber que, no Brasil, há um interesse na autocomposição, parecendo prevalecer a ideia de que um acordo é melhor que a morosidade jurisdicional e que muitas questốes submetidas ao Judiciário não precisariam passar pela decisão de um juiz.

Com o desenvolvimento da percepção de crise do poder Judiciário, em decorrência do crescimento do número de processos judiciais e ante a possibilidade de recursos que esses processos carregam, tais questôes tornaram-se mais fortes, dando ênfase à necessidade de institucionalização da mediaçáo de conflitos judicial.

Assim, o desenvolvimento do processo de mediação de conflitos tem sido relacionado à necessidade de diminuir ou de prevenir os processos judiciais, sendo a celeridade na decisão, ou seja, a possibilidade de se obter um acordo com rapidez, considerada seu principal ponto positivo. Daí, talvez, a realidade de que, historicamente, esse processo tenha sido institucionalizado, mesmo sem lei, a partir da ação de tribunais (BRASIL, 2005), entre os quais o Tribunal de Justiça do Distrito Federal e dos Territórios (TJDFT).

\section{A MEDIAÇÃO DE CONFLLTOS NO TJDFT}

A Resolução $\mathrm{n}^{\circ} 125$ do $\mathrm{CNJ}$ instituiu uma nova política pública para o tratamento de conflitos no âmbito judicial. A partir dela, os tribunais pátrios passaram a ter de criar Centros Judiciários de Solução de Conflitos e Cidadania Cejuscs, vinculados a um Núcleo Permanente de Métodos Consensuais de Solução de Conflitos - Nepumecs (BRASIL, 2010a). 
Não foi sempre assim, contudo. Antes dela, os tribunais interessados em métodos extrajudiciais, como a mediação de conflitos, criavam e regulavam suas próprias atividades conforme seu interesse. Foi dentro desse contexto que o TJDFT criou seu Serviço de Mediação Forense (Semfor), ainda em março de 2002, por meio da Resolução no 2.

Para discorrer sobre esse serviço, faço um resgate de um trabalho de 2008 (DINIZ), fazendo a seguir um resumo dessa obra. Assim, a referida resolução instituiu o Programa de Estímulo à Mediação com os seguintes objetivos:

- Aumentar o poder de decisão das partes sobre as possíveis soluçóes para suas próprias lides;

- Incentivar e inserir a utilizaçáo da técnica da mediação nos procedimentos judiciais, ampliando a possibilidade de resolução de controvérsias com a conseqüente pacificação das partes;

- Promover uma significativa diminuição do tempo de espera da tramitaçáo do processo;

- Diminuir o volume de processos em tramitação nas Varas Cíveis e de Família.

O projeto-piloto desenvolveu-se na regiáo administrativa ${ }^{2}$ de Taguatinga, no Distrito Federal, nas $1^{\text {a }}$ e $2^{\text {a }}$ Varas de Família, Órfãos e Sucessôes e nas $1^{\text {a }}$ e $3^{\text {a }}$ Varas Cíveis. Ele era voluntário às partes, sendo aceita a presença de advogados, casos esses e seus clientes concordassem.

Em relação aos procedimentos, o juiz da vara encaminhava o caso que julgasse pertinente. A partir de entáo, alguém do Semfor entrava em contato com as partes e seus advogados para explicar o procedimento e marcar uma sessáo. Em seguida, os autos do processo judicial eram devolvido à vara de origem, o caso distribuído a um mediador e as partes notificadas oficialmente da primeira sessão. O mediador de conflitos, portanto, não tinha acesso à lide.

2 O Distrito Federal não possui cidades. Ele está dividido em regiōes administrativas, anteriormente chamadas de "cidades satélites", entre as quais está Taguatinga, considerada a capital econômica local. Ver mais em: <http://www.portalbrasil.net/brasil_cidades_brasilia_ras.htm>. Acesso em: 5 mar. 2016. 
A mediação ocorria em sigilo e, ao término, um memorando era encaminhado à vara de origem informando a conclusão dos procedimentos. Em caso de acordo, o termo era encaminhado junto, assinado pelas partes e por seus advogados, para homologação. Na ausência do acordo, uma certidão era enviada sem explicaçóes sobre as razóes ou motivos para o impasse, seguindo o processo judicial seu curso normal. De forma esquemática, o processo era assim:

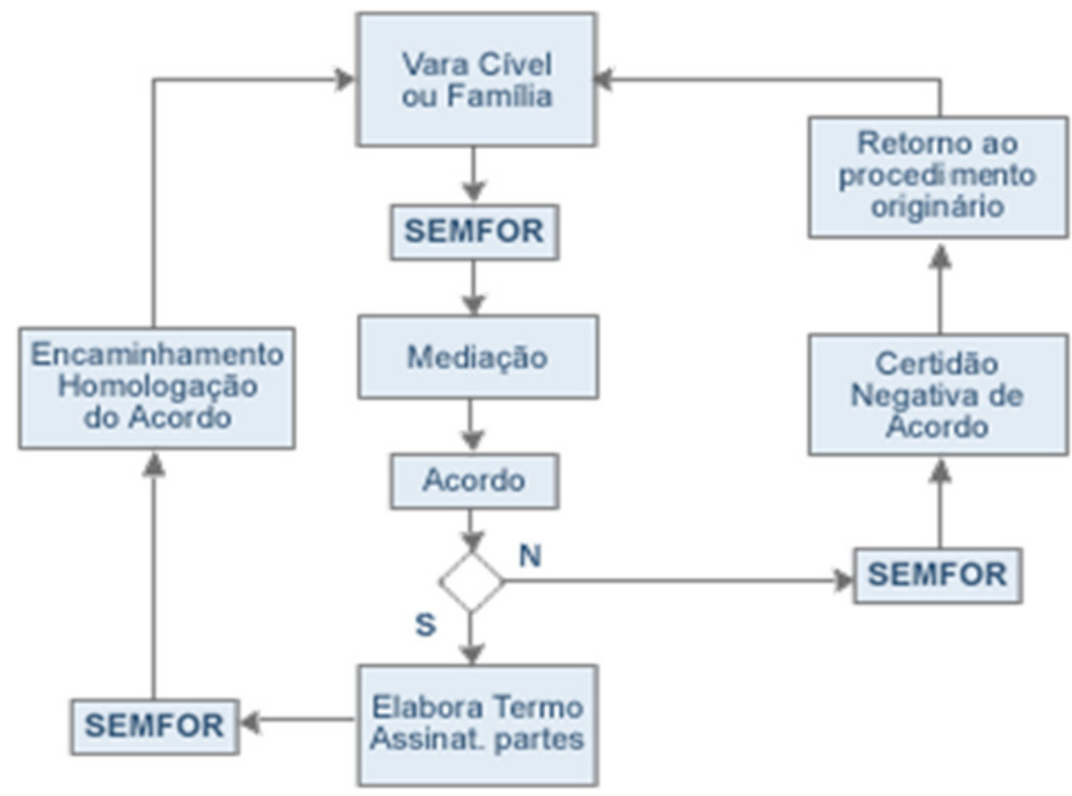

Fonte: DINIZ (2008, p. 246). ${ }^{3}$

Em 2003 o serviço fora ampliado para todas as varas cíveis e de família da circunscriçấo judiciária de Taguatinga e, em 2007, com a Portaria no 406, de 15 de junho de 2007, do Gabinete da Presidência, foi instituído o Centro de Resolução Não Adversarial de Conflitos (CRNC), um setor específico com capacidade de congregar tanto a formação e o desenvolvimento de mediadores judiciais e de

3 O gráfico anteriormente estava disponível no sítio do TJDFT, tendo sido removido. Reproduzo aqui o que foi publicado em 2008, obtido a partir desse original, sendo essa a única referência atualmente disponível. 
multiplicadores como realizar mediaçóes em escala compatível com a demanda de processos de todo o tribunal. Com isso, o Semfor tornou-se autônomo das varas para as quais atuava (DISTRITO FEDERAL, 2007).

Apesar disso, em 2008, logo após o $1^{\circ}$ Congresso Internacional de Mediação de Conflitos, o CRNC foi desarticulado. As experiências de mediação, no entanto, não foram abandonadas, existindo sem a força da institucionalização por um núcleo específico. Tal decisão foi contrária ao movimento que então se consolidava, principalmente após a criaçáo do $\mathrm{CNJ}$, de forma que apenas dois anos depois, a Resolução no 5, de 18 de maio de 2011, do próprio TJDFT, reinstituía a política de mediação de conflitos como resposta à obrigatoriedade surgida com a Resolução $\mathrm{n}^{\circ} 125$ do CNJ (DISTRITO FEDERAL, 2011).

O caso sujeito à análise deste artigo surgira ainda dentro do projeto piloto em Taguatinga, em 2002, cabendo agora dedicar-me a ele.

\section{CONFLITO}

Pensei muito nas diversas formas de apresentação a fim de que a história ficasse o mais clara possível. Náo sei se consegui o intento, mas considerei que pensar num jogo de xadrez poderia ajudar: as peças seriam as pessoas envolvidas, tanto naturais quanto jurídicas; o tabuleiro seriam as relaçóes existentes e as açóes judiciais e, por fim, o jogo seria a forma como cada pessoa interagia com as açóes e as relaçôes instituídas.

Tendo isso em mente, as peças do jogo são Cláudio, João, Maria e José, pessoas físicas, capazes. As jurídicas são as empresas Vidros Ltda., formada da sociedade entre Cláudio e José, e a Latáo Ltda., formada por Cláudio, João e Maria. Há ainda uma instituição financeira, Banco S.A., parte num contrato de arredamento mercantil com a Vidros Ltda., no qual José e Cláudio são fiadores.

As relaçóes existentes são complexas: Cláudio e Maria são cônjuges, casados em comunhão parcial e também sócios entre si e de João, irmão de Maria e, portanto, cunhado de Cláudio. José e Cláudio são sócios na empresa Vidros S.A. e fiadores no contrato entre essa empresa e a instituição financeira Banco S.A. 
Apresentadas as peças, o tabuleiro desenvolve-se entre cinco açóes judiciais. Em ordem cronológica há: separação litigiosa, anulação de escritura pública, cautelar de arrolamento de bens, dissolução de sociedade empresária e alienação judicial e, por fim, ação de reparação de danos. Existem outras açóes envolvendo essas e outras partes, mas para o propósito deste trabalho, esse é o quadro central desenvolvido. A tabela a seguir busca apresentar esse tabuleiro de forma esquemática:

Tabela 1 - Partes, açóes e datas envolvidas no caso

\begin{tabular}{|c|c|c|c|c|}
\hline Data & Ação & Autor & Réu & Finalização \\
\hline 2002 & Separação Litigiosa & Maria & Cláudio & - \\
\hline 2002 & Anulação de escritura pública & Claudio & $\begin{array}{c}\text { João e Banco } \\
\text { S.A }\end{array}$ & 2007 \\
\hline 2002 & $\begin{array}{c}\text { Cautelar de arrolamento de } \\
\text { bens }\end{array}$ & João & Cláudio & 2002 \\
\hline 2002 & $\begin{array}{c}\text { Dissoluçáo de sociedade } \\
\text { empresária }\end{array}$ & João & Cláudio & 2003 \\
\hline 2004 & $\begin{array}{c}\text { Reparação de danos } \\
\text { Vidros } \\
\text { S.A }\end{array}$ & $\begin{array}{c}\text { João, Maria, } \\
\text { Banco S.A, } \\
\text { Cláudio }\end{array}$ & 2011 \\
\hline
\end{tabular}

Fonte: Dados da pesquisa.

Em relação à história, tudo começa em maio de 1992, com o casamento de Maria e Cláudio, empresários, em regime de comunhão parcial de bens, sob a égide do Código Civil de 1916. Aliás, todo o conflito se desenvolve dentro desse marco legal.

Poucos meses depois, em setembro, Cláudio associou-se a José e, juntos, fundaram uma empresa de comércio de vidros e de acessórios, a Vidros Ltda., sendo Cláudio o sócio majoritário e administrador.

Quatro anos mais tarde, em 1996, Cláudio e Maria adquiriram um imóvel e, com João, constituíram a empresa Latáo Ltda., de compra e venda de ferro velho.

Em 1997 a Vidros Ltda. contratou um arrendamento mercantil (leasing) com uma instituição financeira, a Banco S.A., sendo José e Cláudio, os sócios, fiadores. O imóvel onde funcionava a Latão Ltda., de propriedade de Cláudio e Maria, foi alienado fiduciariamente, isto é, dado em garantia, passando à propriedade provi- 
sória do Banco S.A., com usufruto pelos antigos proprietários (Cláudio e Maria) e com garantia de que, após o pagamento do financiamento, a propriedade a eles retornaria. Em suma, a Latão Ltda. continuava a funcionar no local.

Tal empresa, contudo, possuía muitas dívidas, algumas em nome pessoal de João, o terceiro sócio. Diante disso, talvez como uma forma de compensação, ${ }^{4}$ Cláudio transferiu o imóvel onde ela funcionava (e que pertencia a ele e à esposa) ao cunhado, João. A transferência deu-se por instrumento particular, sem registro e sem autorização conjugal (outorga uxória).

Após o término do arrendamento da Vidros Ltda., ao invés de o banco devolver o imóvel a Maria e Cláudio, ele fez a opção de compra em nome de João, transferindo o imóvel por escritura pública de compra e venda, lavrada em cartório em 30 de junho de 2000.

Nesse documento, Cláudio apareceu como único representante da Vidros Ltda. Contudo, desde agosto de 1999, ou seja, um ano antes, houvera alteração contratual tornando José coadministrador. Apesar disso, no ano seguinte, em outubro de 2001, José saiu da Vidros Ltda. e João passou a integrá-la como sócio minoritário, com $10 \%$ do capital social.

A relação entre Cláudio e Maria, no entanto, já não era boa, de forma que, em 2002, foi iniciado um processo litigioso de separaçáo judicial, transcorrido na $3^{\text {a }}$ Vara de Família, Órfãos e Sucessôes de Taguatinga, à época não sujeita ao Semfor. Nesse processo, entre os bens para a partilha não constou o imóvel transferido a João, por não integrar o patrimônio do casal em decorrência da transferência realizada pela instituição financeira.

Diante disso, Cláudio ingressou com ação de anulação de escritura pública contra João e o Banco S.A., com pedido de suprimento de outorga uxória (diante da separação litigiosa) e de adjudicação compulsória do imóvel. Como a ação apresentava litisconsórcio passivo com um banco estatal, o processo foi encaminhado à vara competente.

4 Em 21 de maio de 2004, numa audiência de instrução e julgamento de uma ação de despejo, Maria declarara, sem prestar compromisso, em razão de parentesco, que a passagem se deu para garantir um empréstimo bancário. 
Diante desses dois processos (separação judicial e anulatória), cinco meses depois, em novembro de 2002, João deu entrada em ação cautelar de arrolamento de bens, preparatória de ação de dissolução da sociedade Vidros Ltda., argumentando receio de dilapidação de patrimônio pelo fim da affectio societatis. A ação principal foi apresentada em seguida, com pedido de declaração de dissolução de sociedade e de alienação judicial, ambas distribuídas para uma vara sujeita ao Semfor.

$\mathrm{Na}$ ação cautelar a audiência de justificação foi marcada para o dia 10 de dezembro, ocasiāo em que o juiz, após recebimento de declaraçóes, apresentou o Semfor, e as partes, João e Cláudio, concordaram com a tentativa de mediação, entâo inédita. Assim, é preciso entender que o processo de mediação de conflitos desenvolveu-se apenas quanto à ação cautelar.

A primeira sessão ocorreu em 11 de dezembro, logo culminando em acordo. Satisfeitas, as próprias partes solicitaram nova sessão, dessa vez para a ação principal. Não constam nos autos informaçóes sobre essa sessão, salvo o pedido de notificação urgente, havendo apenas a menção de que, em 6 de março de 2003, as partes apresentaram em conjunto um termo de transação no qual João deixava de integrar a Vidros Ltda. e José retornava como coadministrador. Ambos os processos, cautelar e de dissolução societária, foram encerrados com a homologação em 28 de abril de 2003.

Apesar desse aparente sucesso, o processo de anulação de escritura pública ainda corria na Vara de Fazenda Pública, encerrando-se somente em junho de 2007 com a improcedência do pedido. O processo, no entanto, alcançou as mais altas instâncias, chegando a Agravo de Instrumento em Recurso Especial e Extraordinário, no Superior Tribunal de Justiça (STJ) e no Supremo Tribunal Federal (STF), respectivamente.

Antes disso, porém, ainda em março de 2004, Cláudio afastou-se da Vidros Ltda., permanecendo José como administrador. No ano seguinte, em agosto de 2005, a empresa, por meio de seu representante, José, ingressou com ação de reparação de danos contra o Cláudio, Maria, João e o Banco S.A, processo que transitou em julgado em 6 de julho de 2011, de forma favorável ao autor. 


\section{ARGUMENTAÇÕES E ESTRATÉGIA}

Em relação aos aspectos que pareceram influenciar as estratégias e a argumentação das partes, lembro que os conflitos ocorreram em relaçóes multiplexas, com forte carga afetiva e emocional, que condicionaram o agir estratégico. Além disso, a mediaçáo de conflitos ocorrera apenas em um dos processos judiciais, mesmo havendo ainda um conflito de fundo que lhes dera causa ou os acirrou, extrapolando as próprias partes da mediação de conflitos: a separação litigiosa.

É bem verdade que antes da ação judicial já existiam conflitos. Seria ingenuidade considerar que tal açáo tenha dado causa a eles. O que ela faz é publicizar as relaçôes privadas, que, até entâo, pareciam funcionar sem judicialização. Assim, se João e Cláudio são sócios, são também cunhados e, no momento das açôes de dissolução de sociedade, estão ambos emocionalmente envolvidos na separação litigiosa entre Cláudio e Maria. Tanto é assim que Cláudio ingressa com a primeira ação porque um imóvel não figura entre os bens a serem partilhados no litígio do casal, imóvel esse que havia sido transferido pelo próprio Cláudio, sem o consentimento expresso de Maria, coproprietária e sócia.

Nessa ação, a linha de argumentação obedece a três eixos, relacionados ao descumprimento de dispositivos do Código Civil então em vigor. O primeiro lembra que a transmissão se deu por instrumento particular, quando deveria ser por escritura pública, o que sujeitava à nulidade do negócio. $\mathrm{O}$ segundo eixo considera a ilegalidade da parte contratante, pois quem aparece no contrato é a Vidros Ltda., que não era proprietária do imóvel. O último eixo trata da ausência de autorização conjugal (outorga uxória), essencial para a legalidade do ato. Esse último eixo existiu porque, para Cláudio, Maria estaria de "conluio" com o irmão para prejudicá-lo na partilha dos bens.

O argumento de "conluio" vai ser utilizado diversas vezes ao longo de todos os processos, evidenciando o aspecto emocional e o conflito de fundo. Tal aspecto é tâo forte que causa confissão de negócios simulados como estratégia processual: João não teria condiçóes financeiras para adquirir o imóvel. Assim, passar o imóvel para seu nome fora apenas um ato realizado na base da "confiança" e com expressa determinação de ser desfeito. Seu objetivo seria apenas facilitar futuros contratos das empresas envolvidas. 
Como esse processo de anulação de escritura pública possuía litisconsórcio passivo com um banco público, foi encerrado sem julgamento do mérito na Vara de Registros Públicos e encaminhado à Vara responsável, de Fazenda Pública.

Quanto a João, sua estratégia foi similar. Logo após a ciência da ação de anulação, ingressou com a ação cautelar para arrolamento de bens, sob argumento do fim da affectio societatis e de risco de dilapidação patrimonial. A açáo principal reproduziu tais argumentos e acrescentou que autor até já teria tentado vender suas cotas ao réu, por $R \$ 50.000,00$ ( $R \$ 124.739,14$ nos valores de janeiro de 2017), o que havia sido infrutífero. Há, aqui, um movimento negocial dentro do processo judicial: João indica estar disposto a negociar e apresenta o lance inicial.

Em resposta, Cláudio contestou e deu entrada em ação de impugnação ao valor da causa. $\mathrm{Na}$ contestação ele manteve a estratégia de confessar a falsidade dos negócios ao afirmar que: a) a sociedade com João era uma farsa - ocorrera apenas para que Cláudio constituísse a sociedade, pois na prática esse seria o único empresário; b) João não teria renda, daí não ter havido integralização do capital social. Mas também aqui há seguimento ao movimento negocial: Cláudio se interessa na compra das cotas, mas questiona o valor solicitado sob o argumento de que a empresa operaria "no vermelho", sem, contudo, apresentar comprovação.

Em réplica, João reafirmou a integralização do capital social e rebateu as informaçóes de Cláudio, afirmando que a empresa possuía valores em estoque, que ela seria "a mais rentável do ramo" e por ter um significativo faturamento mensal. Além disso, também mencionou possibilidade de irregularidades como: a) "caixa dois", por ausência de depósitos em cheque; b) desvio, com possibilidade de o dinheiro em cofre estar sendo depositado em contas pessoais de Cláudio; c) esvaziamento de estoque por aberturas de outras sociedades, sugerindo a necessidade de vistoria pelo Ministério Público (mas sem apresentar os nomes das empresas envolvidas). Por fim, impugnou os documentos apresentados, justificou o valor pedido por suas cotas, mas sem apresentar provas, e indicou a possibilidade de comprar as cotas do réu, desde que os documentos sobre a real situação empresarial fossem apresentados. 
O que se vê, assim, é que o cerne desses processos é o movimento negocial do tipo ganha-perde intermediado pelo processo judicial. Como as alegaçóes feitas náo são provadas, servem apenas como tergiversaçóes e como forma de conduzir as negociaçóes. Todo o aspecto jurídico é apenas um subterfúgio que camufla as reais posiçóes das partes e esconde o conflito de fundo.

\section{DO PROCESSO DE MEDIAÇÃO E DA DECISÃO}

Todo esse componente emocional foi logo percebido na audiência de justificação no processo cautelar, razáo pela qual o juiz apresentou o Semfor e seu ineditismo. No dia seguinte, a mediação alcançou o seguinte acordo:

O réu (Cláudio) concorda em dar em garantia a eventual execução futura na ação principal, $50 \%$ do imóvel, relativos à meação do autor e sua fração ideal nessa propriedade.

Com relação às questôes tratadas nos autos da ação de dissolução de sociedade, concordam as partes a se submeter ao processo de mediação para, eventualmente, compor a controvérsia.

Assim, garantiram-se os valores para a ação principal e as partes concordaram com outra sessão para efetivar a negociação que começara a ser traçada dentro do processo judicial. A sentença de homologação desse acordo e de extinção da ação considerou que o Semfor gerou uma composição eficaz e estruturou o conflito de interesses existente, atendendo ao objetivo para o qual havia sido criado. Em outras palavras, o Semfor foi eficaz em reconhecer esse movimento negocial e em tentar transformá-lo numa negociação do tipo ganha-ganha.

A sentença considerou ainda que questóes cíveis e comerciais seriam perfeitamente adequadas à mediação forense, cabendo ao juiz avaliar se o litígio poderia ser mediado conforme a "especificidade da relação jurídica existente". Qual seria tal especificidade não foi esclarecido, mas, a partir da teoria da mediação de conflitos, é possível que se trate do aspecto emocional presente, ideia reforçada ao se considerar que, no processo de anulação de escritura pública, esse aspecto também fora percebido, conforme expressa a sentença que se segue: 
O ponto nodal da demanda refere-se ao fato de que o requerido, João, também é sócio da empresa e irmáo da ex-esposa do autor. Verifica-se nos autos que o autor já estava de má-fé, porque ao invés de retornar o imóvel que estava em nome do casal, para este, após a quitação da dívida, não o fez; não se sabe a título de quê o autor transferiu o imóvel para o seu cunhado João.

Agora, após a separaçáo judicial do casal, o autor vem a juízo alegar que o ato jurídico é nulo pela simulação. Ocorre que quem elaborou a própria simulação foi o autor. Assim, está pretendendo se valer do próprio dolo para anular o negócio jurídico por ele simulado. O próprio autor faz prova (...) que não arrolou o imóvel [...] na ação de separação judicial litigiosa (grifo nosso).

Assim, tal decisão percebe o aspecto emocional envolvido (as relaçóes de parentesco e o divórcio). Contudo, numa vara que não pode realizar ou encaminhar para a mediação de conflitos, a única opção que há é a decisão com base nos aspectos eminentemente jurídicos. Daí a decisão valer-se da simulação e não do relacionamento - mesmo que esse tenha sido percebido como "ponto nodal". Esse dado expressa a necessidade da institucionalização do mediaçáo, sob pena de que causas inter relacionadas não poderem ser efetivamente resolvidas.

Apesar de as partes terem aceitado uma nova sessão de mediação de conflitos, não constam nos autos informaçóes sobre ela, salvo o pedido de notificação urgente. Ainda assim, em março de 2003, elas apresentaram em conjunto o seguinte termo de transação:

O Réu da presente demanda [Cláudio], dará os direitos decorrentes da presente ação, representados pelos valores das cotas da Empresa objeto da demanda, a quantia de R \$20.000,0 (vinte mil reais) em moeda corrente do país, dando de forma recíproca plena e rasa quitação ao objeto da presente ação, para não mais reclamar em juízo e/ou fora dele.

O Réu, em face do acordo, assume perante o fisco Estadual e Federal todos os débitos ali existentes, bem como todas as dívidas (...), débitos trabalhistas existentes e futuros, desonerando o Autor [João] de quaisquer responsabilidades de valores da empresa desde a sua constituição até a presente data. 
O Réu compromete-se no prazo de 5 (cinco) dias a contar do (Sic) presente data, a proceder a alteração contratual junto à Junta de Comércio bem como junto às Receitas Estadual e Federal, retirando o nome do Autor da condiçáo de sócio da empresa objeto da presente demanda (...).

Dessa forma, as partes deram continuidade ao processo negocial, chegando a um acordo que encerrou tanto a cautelar quanto a ação principal. Ainda assim, os demais litígios continuaram, com o término final de todos somente em 2011.

\section{ANÁLISE E DISCUSSÃo}

Para a análise e discussão do caso faço uso da teoria dos conflitos, tendo como base Deustch (2004) e Entelman (2002), além de autores como Azevedo (2004), Barbado (2003), Six (2001) e Warat (2004), entre outros. São muitos os pontos a serem analisados e, como já afirmado, esse não se pretende ser um trabalho exaustivo e definitivo. Diante disso, tomo como eixos de discussáo: cabimento, partes, litigiosidade remanescente, modelo de mediação e, por fim, a efetividade do processo.

Em relação ao cabimento, parece haver um consenso de que, como a mediação de conflitos busca eliminar o caráter adversarial habitualmente observado no litígio judicial, ela deve ser utilizada quando os demais métodos não puderem satisfazer às necessidades e aos interesses emocionais, econômicos e psicológicos das partes. Isso significa que ela se mostra adequada quando as partes possuem um vínculo emocional-afetivo; quando o conflito exija sigilo e manutenção de relacionamentos; quando houver necessidade de flexibilidade para a comunicação e para a manifestação de prioridades e desejos e, por fim, quando houver interesses náo tutelados pelo Estado (COOLEY, 2001; ALMEDIDA, 2003, AZEVEDO, 2004; WARAT, 2004). Todos esses aspectos estão presentes no caso em concreto, o que sugere serem essas, inicialmente, a razáo para o sucesso do Semfor.

Contudo, um ponto essencial é que, a despeito desses critérios, o procedimento autocompositivo só foi realizado em razão de dois pressupostos: a) sua institucionalização; e b) a percepção do juiz quanto a sua possibilidade. 
Assim, primeiramente, é necessário que seja possível encaminhar os casos à mediação de conflitos. No processo de anulação de escritura pública, apesar da percepção do juiz de que haveria um vínculo emocional entre as partes, o que permitiria o acesso à mediaçáo, isso fora impossível, pois a vara náo estava vinculada ao Semfor.

Não havendo essa possibilidade, a sentença do processo de anulação de escritura pública teve de ser baseada exclusivamente na análise da simulação praticada e nos documentos dos autos, culminando na consequente sançáo, ou seja, o indeferimento do pedido. Tal processo não pode considerar as questóes de fundo, que motivam as partes a agirem da forma como agem, compreendê-las e buscar transformaçóes prospectivas. Da mesma forma, náo foi possível compreender que os processos que se seguiram à separaçáo litigiosa foram utilizados de forma estratégica para interferir nas relaçóes privadas existentes e resolver as questóes.

De fato, nada disso integra o processo judicial. Tal como Almeida (2003) e Barbado (2003) consideraram, se é o Estado que resolve o litígio, seu critério norteador será seu próprio interesse, que pode não corresponder ao das partes. Seu interesse, no caso, poderia ser estabelecer o direito, proteger a confiança jurídica ou, conforme Fiss (2004), declarar os valores nos quais se fundamentou. Em qualquer situação, não há resolução do conflito, e sim apenas a solidificação da decisão judicial.

A despeito disso, diante da atual política pública esse quesito talvez se mostre desatualizado. Isso porque Nepumecs e Cejuscs devem atuar por todo o tribunal a que se sujeitam. Contudo, ele reforça a necessidade de institucionalizaçáo, evidenciando que, sem ela, não há efetividade de decisóes. Ou seja, caso os Nepumecs e Cejuscs não sejam efetivamente instrumentalizados, o instituto da mediação de conflitos judicial não terá o condão de efetivar seus efeitos.

Além disso, é preciso lembrar que o envio ao Semfor dependeu do análise pelo juízo da causa, verificando sua adequação à mediação. Nesse ponto, o primeiro passo para uma efetivação seria que tal profissional tivesse consciência dos casos passíveis ou não de mediaçáo de conflitos, o que reforça a necessidade de formaçáo e sensibilização de magistrados. A institucionalização da mediaçáo de conflitos não será efetiva sem a participação ativa deles, pois, ainda que não sejam mediadores ou partes, serão promotores da política pública. 
Em suma, em relação ao cabimento da mediação de conflitos, o caso em tela demonstrou que a existência de relaçôes multiplexas e de disponibilidade das partes é essencial para a efetividade do caso. É também importante, contudo, que magistrados reconheçam essas peculiaridades e que sejam capazes de encaminhar os processos para a área devida, bem como, antes disso, que eles tenham para onde fazê-lo. Sem isso, não há como haver sucesso ao instituto da mediação de conflitos forense.

Já em relação às partes, verifica-se uma complexidade maior do que inicialmente vista no processo de mediação de conflitos. O procedimento autocompositivo se desenvolveu entre entre João e Cláudio, sócios e cunhados, porque eram eles que integraram a lide sujeita ao Semfor. Contudo, o conflito em si envolve outras partes: Maria, José, as empresas Vidros Ltda. e Latão Ltda. e até o Banco S.A., nenhuma das quais foi ouvida.

Entelman (2002) e Deustch (2004) consideram que cada uma das partes que integra um conflito relaciona-se, em maior ou menor grau, com todas as demais. Isso significa que qualquer tratativa de mediação, para ser eficaz, deveria considerar todas essas partes e não apenas a lide instituída. O processo inicial de análise multifatorial do conflito é justamente esse: identificar quem possui poder sobre a transformação do conflito.

Isso não aconteceu no caso concreto. $\mathrm{Na}$ verdade, houve uma confusão entre lide (o conflito de interesses específico, manifestado em juízo) e o conflito efetivamente existente. Dentro dessa confusão - bem como em razão da forma como a institucionalização se deu - não houve reunião de lides, tendo a mediação se realizado sem menção aos conflitos inter-relacionados e processualmente distantes.

Esse ponto me faz lembrar, ainda em relação às partes, que, apesar de haver as que originalmente integraram o conflito, diretamente interessadas, outras existiram com poder de influenciar o conflito e os procedimentos que se seguiram: os advogados e os mediadores.

Quanto aos advogados, teoricamente, seriam eles que teriam as melhores condiçóes de detectar a possibilidade de mediação, pois foram os profissionais que tiveram conhecimento de todos os processos e incidentes processuais. 
Eles conheciam as interligaçóes e as motivaçóes de cada uma das partes, sendo que cada ação processual se deu em decorrência das suas estratégias jurídicas. Além disso, todas a demanda foi colocada em juízo a partir do filtro realizado por esses profissionais: a análise das petiçóes nos autos não é a análise da fala das partes, mas do discurso dos advogados, a partir do filtro que eles decidiram utilizar. Por fim, na ausência de uma segunda sessão de mediação de conflitos, foram eles responsáveis pela efetivação da transação que deu fim aos processos.

Em outras palavras, a atuação desses profissionais foi essencial para todo o andamento do conflito existente, inclusive quanto ao acirramento, decorrente de sua estratégia de ação. De fato, os processos mostraram uma demanda contínua ao Poder Judiciário, o uso de argumentos pouco técnicos e a utilização do processo judicial como subterfúgio para obrigar a um acordo. A argumentação utilizada deu ênfase aos aspectos emocionais em detrimento de teses jurídicas, inclusive com justificação para simulaçôes, tergiversaçôes, declaraçôes e afirmaçôes que não poderiam ser comprovadas, além da ênfase de que toda a situação fora criada em razão da relação de confiança existente entre as partes.

Nisso, o processo judicial foi utilizado apenas como meio de obrigar a uma negociação, fortalecendo posiçóes negociais: os lances foram diretamente trocados, uma parte tentando comprar pelo menor e a outra tentando vender pelo maior, numa negociação distributiva, ou seja, baseada em percepçôes de ganha e perde e em que as estratégias (tergiversação, apresentação de dados sem relação com o objeto principal e sem comprovação) serviram apenas para valorizar as posiçóes e permitir a continuação do processo.

É notório, todavia, que essas açôes são rotineiras na profissão. Assim, a formação desse profissional ainda é um tema a ser considerado, pois se, àquela época, não havia uma formação voltada para a atuação advocatícia diante da mediação, atualmente esse paradigma tem mais chances de ser alterado com a institucionalização. Contudo, Schmitz (2003) receia que mesmo os cursos direcionados à autocomposiçáo não consigam afastar os advogados de sua formação original se forem focados no repasse de técnicas. Para a autora, a formação deve ser permanente, voltada a uma nova postura ante o conflito e para a aquisição de competências, não apenas conhecimento, o que também leva à reflexão sobre o mediador de conflitos. 
Conforme percebido, o mediador também não fora capaz de realizar uma análise multifatorial, identificando os interesses subjacentes, desenvolvendo relacionamentos cooperativos e explorando estratégias que prevenissem ou resolvessem as controvérsias. Em verdade, fora o mediador quem confundiu lide e conflito, resolvendo apenas a lide e sequer compreendendo o caso como um todo (a questáo do casamento e da separação, a formação de uma sociedade empresária familiar, as consequências dos atos para terceiros).

Essa questão talvez tenha relação com o tipo de modelo de mediação de conflitos adotado, mais próximo ao tradicional linear, com ênfase à busca do acordo como forma de sucesso do procedimento. Nesse processo, o mediador apenas intermedeia as barganhas, buscando mudar a postura do tipo ganha-perde, para ganha-ganha, o que foi visto no caso em questáo. Talvez por isso o processo tenha sido concluído de forma rápida.

Ao funcionar dessa forma, a mediaçáo colaborou para o encerramento da lide, mas não do conflito como um todo, principalmente se considerarmos que não houve a participação de todos os envolvidos, como desejavam Entelman (2002) e Deustch (2002).

Assim, a partir do caso concreto, parece que a mediaçáo focada no conflito ao invés do acordo é mais adequada a situaçóes semelhantes. Isso porque, a partir de Bush e Folger (2005), Warat (2004) e Six (2001), a mediação de conflitos deve permitir que as partes resolvam suas disputas construtivamente, fortalecendo as relaçóes sociais, identificando interesses subjacentes, desenvolvendo relacionamentos cooperativos e explorando estratégias que previnam ou resolvam futuras controvérsias. Dentro desse modelo, parece haver maior probabilidade de que o conflito seja compreendido como um todo, aumentando a chance de que os demais processos também fossem influenciados pela mediação.

Contudo, reconheço a necessidade de se aprofundar essa questão: fora a formação do mediador ou o modelo escolhido que não pode efetivamente lidar com o conflito? Em qualquer situação, como uma mediação transformadora poderia se desenvolver no meio judiciário, dentro de uma política que visa à quantidade de acordos e de encerramento de lides em detrimento de transformaçóes humanas, também permanece como questão. 
Seja como for, o que se viu é que ocorreu o contrário do pretendido por qualquer modelo de mediação de conflitos: a perpetuação da litigiosidade remanescente.

Litigiosidade remanescente, para Barbado (2003) e Azevedo (2004), que adoto aqui, seria o desejo de permanecer litigando mesmo após o término de uma lide em decorrência das questôes não resolvidas no processo judicial. Com isso, as partes permanecem criando condiçóes para que o conflito se perpetue, seja mediante novos processos judiciais, seja por meio de incidentes nos processos já existentes, gerando repercussôes econômicas e materiais para as pessoas e para o sistema judiciário como um todo.

Nesse aspecto, é interessante lembrar que o primeiro caso de mediação forense do Semfor não foi, em si, um caso originário. Ou seja, ele nasceu de um conflito anterior, inclusive, à época, já institucionalizado: a separação litigiosa. Esse processo, contudo, náo foi submetido à mediação de conflitos, uma vez que o projeto-piloto não abarcara a vara na qual ele tramitava, ou seja, a mediação já atuou num processo surgido dentro de uma litigiosidade remanescente.

Em outras palavras, mesmo que o processo de mediação tenha pontualmente encerrado uma lide e gerado satisfação às partes (demonstrada pela solicitação de nova sessão), ao se analisar a totalidade do caso, ele não conseguiu manter os laços afetivos, nem exaurir a litigiosidade existente. Ao contrário: os processos e incidentes continuaram multiplicando-se até atingirem a mais alta corte. Em suma, ele foi, pontualmente, um sucesso, porém, dentro da análise multifatorial do conflito, infrutífero.

As razôes para tal são intrínsecas à realidade do caso concreto e talvez não se justifiquem se considerado o estado da arte atual, ou seja, a forma como tem se desenvolvido a mediação na atualidade. Ainda assim, considero que o caso traz importantes reflexôes para a atualidade, com espaço para novas pesquisas.

\section{8 À GUISA DE CONCLUSÃO?}

A mediação, como forma de resolução de conflitos, institucionalizada no âmbito dos tribunais, é uma realidade. Do caso aqui analisado, de 2002, até os dias de hoje, já são quase 15 anos, tempo suficiente para a revisão de métodos e tecno- 
logias. Tenho plena consciência que, do modelo do Semfor até o atual Nepumec, muita coisa mudou, cabendo, nesse ponto, mais pesquisas e estudos de caso para confirmar ou não as questôes aqui apresentadas.

Ainda assim, o presente trabalho tem o condão de provocar um debate sobre a evolução do instituto. $\mathrm{O}$ caso aqui em análise demonstrou a importância de que o modelo seja aplicado universalmente, sob o risco de que conflitos inter-relacionados não possam ser analisados.

Atualmente, por meio da Portaria no 125 do $\mathrm{CNJ}$, a mediação de conflitos está em todos os tribunais e é amplamente utilizada. Contudo ainda cabem questionamentos sobre o procedimento para processos nas diversas varas ou circunscrições. Uma mediação, para ser efetiva, não deve apenas encerrar um processo, e sim interferir no conflito e nas pessoas envolvidas, sob pena de náo atuar eficazmente sob a litigiosidade remanescente. Só assim o conflito de fundo e os reais anseios das partes podem ser compreendidos e atendidos. Isso significa, no entanto, a possibilidade de que um caso sujeito à mediação de conflitos possa ser analisado de forma ampla, abarcando, inclusive, mais de um processo, vara ou circunscrição que, talvez, a forma atual prevista não tenha conseguido ainda estabelecer.

Pelo mesmo motivo, o objetivo da mediação não pode ser um simples acordo, mesmo que satisfatório. Um acordo, em si, não significa a resolução do conflito, conforme se verificou. Um processo encerra-se por um acordo, mas outros permanecem ou novos surgem, o que demonstra que essa estratégia simplesmente não transforma a relação conflituosa nem fomenta uma efetiva paz social.

Tenho consciência de que mais pesquisas buscando relacionar o encerramento de processos nesse tipo de relação serão necessárias. Ainda assim, o presente caso sugere que a mediação tradicional linear pode apresentar pontos falhos quando o conflito envolver aspectos emocionais e der origem a ramificações conflituosas. Quanto a isso, se a vertente transformadora não é aplicada, seria importante que o mediador percebesse o caso como integrante de um todo maior e questionasse, sempre, sobre outros processos existentes entre as partes em mediação, tentando, a partir dessa informação, trabalhar de forma mais ampla. 
A mediação como um todo, e especificamente a mediação judicial, deve buscar a real diminuição da litigiosidade entre os pares, o empoderamento das partes na resolução de seus futuros conflitos e a internalização de que o conflito pode ser dirimido de forma autônoma, por cada um, sem se recorrer ao Poder Judiciário. Quanto a isso, a atuação advocatícia é um fator importante, pois, conforme visto, ela tem a faculdade de acirrar o conflito de fundo. Nesse ponto, talvez a institucionalizaçáo da mediação por meio de uma política pública tenha o poder de despertar o interesse do profissional, de cursos de graduação e de pós-graduação, o que pode mudar a atuação no futuro. Contudo, isso só se dará de fato se a formação sair do sistema de aquisição de conhecimentos e partir para aquisição de competências.

Por fim, cabe lembrar que o presente caso apresentou um importante passo no desenvolvimento de um sistema de resolução de conflitos no Brasil: foi a primeira atuação de um projeto que continuou a se desenvolver até os dias atuais. Cabem agora novas pesquisas, sobre novos casos, que permitam uma maior compreensão do instituto da mediação judicial de conflitos.

\section{REFERÊNCIAS}

ADAD, Clara Jane. Candomblé e Direito: o encontro de duas cosmovisóes na problematizaçáo da noção de sujeito de direito. Brasília, 2015. Dissertação (Mestrado) - Universidade de Brasília. Programa de Pós-Graduação em Direitos Humanos e Cidadania, Centro de Estudos Avançados Multidisciplinares, Brasília, 2015.

ALMEIDA, Fábio Portela Lopes de. A teoria dos jogos: uma fundamentação teórica dos métodos de resolução de disputa. In: AZEVEDO, André Gomma de (Org.). Estudos em arbitragem, mediação e negociação. Brasília: Grupos de Pesquisa, 2003, p. 175-199. Vol. 2.

AZEVEDO, André Gomma de. Autocomposição e processos construtivos: uma breve análise de projetos-piloto de mediação forense e alguns de seus resultados. In: AZEVEDO, André Gomma de (Org.). Estudos em arbitragem, mediação e negociação. Brasília: Grupos de Pesquisa, 2004. Vol. 3

BARBADO, Michelle Tonon. Um novo perfil para a advocacia: o exercício profissional do advogado no processo de mediação. In: AZEVEDO, André Gomma de (Org.). Estudos em arbitragem, mediação e negociação. Brasília: Grupos de Pesquisa, 2003. Vol. 2. 
BARBOSA, A. A. Composição da historiografia da mediação - instrumento para o direito de família contemporâneo. Direitos Culturais, Santo Ângelo, R. S: Universidade Regional Integrada, n. 3, vol. 2, p. 11-21, dez. 2007. Disponível em: <http://srvapp2s.urisan.tche.br/ seer/index.php/direitosculturais/article/view/94/74>. Acesso em: 13 abr. 2013.

BRADLEY, S. SMITH, M. Community Mediation: Reflections on a Quarter Century of Practice. Mediation Quarterly, vol. 17, n. 4, p. 315-320, 2000.

BRASIL. Acesso à justiça por sistemas alternativos de administração de conflitos: mapeamento nacional de programas públicos e Ministério da Justiça não governamentais. Brasília: Ministério da Justiça, 2005. Disponível em: <http://www.acessoajustica.gov.br/pub/_downloads/ downloads_acesso_justica.pdf> Acesso em: 28 set. 2015.

. Conselho Nacional de Justiça. Resolução n. 125, de 29 de novembro de 2010, dispóe sobre a Política Judiciária Nacional de tratamento adequado dos conflitos de interesses no âmbito do Poder Judiciário e dá outras providências. 2010a. Disponível em: <http://www.cnj.jus.br/ busca-atos-adm?documento=2579>. Acesso em: 28 set. 2015.

Decreto-lei n. 1.572, de 28 de julho de 1995, que regulamenta a mediação na negociação coletiva de natureza trabalhista e dá outras providências. Diário Oficial da União, de 31 de julho de 1995. 1995a. Disponível em: <http://www.planalto.gov.br/ccivil_03/ decreto/1995/D1572.htm>. Acesso em: 15 jul. 2014.

. Lei n. 13.140, de 26 de maio de 2015, dispóe da mediação extrajudicial e da autocomposição junto à Administração Pública. 2015a. Disponível em: <http://www.planalto.gov.br/ ccivil_03/_Ato2015-2018/2015/Lei/L13140.htm>. Acesso em: 28 set. 2015.

. Lei n. 13.105, de 16 de março de 2015, Código de Processo Civil. 2015b. Disponível em: <http://www.planalto.gov.br/ccivil_03/_Ato2015-2018/2015/Lei/L13105. htm\#art1045>. Acesso em: 28 set. 2015.

. Lei n. 3.071, de $1^{\circ}$ de janeiro de 1916, Código Civil dos Estados Unidos do Brasil [revogado pela Lei n. 10.406, de 2002]. Disponível em: <http://www.planalto.gov.br/ccivil_03/leis/L3071.htm>. Acesso em: 28 set. 2015.

. Lei n. 556, de 25 de junho de 1850, Código Comercial. Disponível em: <http://www. planalto.gov.br/ccivil_03/leis/L0556-1850.htm>. Acesso em: 28 set. 2015.

Lei n. 9.099, de 26 de setembro de 1995, que dispóe sobre os Juizados Especiais Cíveis e Criminais e dá outras providências. 1995b. Disponível em: <http://www.planalto.gov.br/ ccivil_03/Leis/L9099.htm>. Acesso em: 28 set. 2015. 
BRASIL. Lei no. 10.101, de 19 de dezembro de 2000, que dispóe sobre a participação dos trabalhadores nos lucros ou resultados da empresa e dá outras providências. Diário Oficial da União, de 20 de dezembro de 2000. Disponível em: <http://www.planalto.gov.br/ccivil_03/ leis/l10101.htm>. Acesso em: 15 jul. 2014.

. Programa Nacional de Direitos Humanos (PNDH-3). Secretaria Especial dos Direitos Humanos da Presidência da República. Brasília: SEDH/PR, 2010 b.

BUSH, R. A. B. FOLGER, J. P. The promise of mediation: the transformative approach to conflict. San Francisco: Jossey-Bass A Wiley Imprint, 2005.

CALMON, Petrônio. Fundamentos da mediação e da conciliação. Rio de Janeiro: Forense, 2007.

CLASTRES, Pierre. Arqueologia da violência - pesquisas de antropologia política. São Paulo: Editora Cosac \& Naify, 2004.

COBB, Sara. A narrative perspective on mediation: toward the materialization of the "storytelling” metaphor. In: FOLGER, Joseph. JONES, Tricia S. New directions in mediation: comunication, research and perspectives. California: Sage Publications, 1994.

COHEN, Jerome Alan. Chinese Mediation on the Eve of Modemization. California Law Review, n. 54, v. 2, p. 1.201-1.226, 1966. Disponível em: <http://scholarship.law.berkeley.edu/ cgi $/$ viewcontent . cgi? article $=2913 \&$ context $=$ californialawreview $>$. Acesso em: 15 jun. 2014 . COOLEY, John W. A advocacia na mediação. Brasília: UnB, 2001.

COSTA, Alexandre Araújo. Cartografia dos métodos de composição de conflitos. In: AZEVEDO, André Gomma de. Estudos em arbitragem, mediação e negociação. Brasília: Grupos de Pesquisa, vol. 3, p. 161-201, 2004.

DEUTSCH, Morton. A resolução do conflito. In: AZEVEDO, André Gomma de (Org.). Estudos em arbitragem, mediação e negociação. Brasília: Ed. Grupos de Pesquisa, 2004. p. 29-40. V. 3.

DINIZ, B. S. A mediação judicial no TJDFT: um novo espao de atuação. Revista dos Estudantes de Direitos da Universidade de Brasília. Brasília: Jurisprodigium, n. 7, vol. 1, p. 269-294, 2008.

DISTRITO FEDERAL. Programa justiça comunitária. Brasília: Tribunal de Justiça do Distrito Federal e dos Territórios (TJDFT), 2012. Disponível em: <ftp://ftp.cnj.jus.br/ conciliacao/2012/CATEGORIA\%20TRIBUNAL\%20ESTADUAL/TJDFT\%20-\%20NUPECON\%20-\%20JUSTI\%C7A\%20COMUNIT\%C1RIA/Premio\%20Conciliar\%20-\%20 Programa\%20Justi\%C3\%A7a\%20Comunit\%C3\%A1ria.pdf>. Acesso em: 28 set. 2015. 
DISTRITO FEDERAL. Tribunal de Justiça do Distrito Federal e dos Territórios. Politica Judiciária Nacional: implantação da política judiciária nacional de tratamento adequado dos conflitos de interesses no âmbito do TJDFT. Disponível em: <http://www.tjdft.jus. $\mathrm{br} /$ institucional/2a-vice-presidencia/nupemec/politica-judiciaria-nacional>. Acesso em: 28 set. 2015.

. Portaria GPR no. 406, de 15 de junho de 2007, instituí o Centro de Resolução Não-Adversarial de Conflitos - CRNC. Diário de Justiça, de 4 de julho de 2007, Seção 3, fl. 117. 2007. Disponível em: <http://www.tjdft.jus.br/publicacoes/publicacoes-oficiais/ portarias-gpr/2007/00406.html>. Acesso em: 28 set. 2015

. Resolução no 5, de 18 de maio de 2011, Dispóe sobre a política judiciária de tratamento adequado dos conflitos de interesses no âmbito da Justiça do Distrito Federal. Diário da Justiça Eletrônico [DJ-E] de 19 de maio de 2011, edição n. 93, fl. 4-6. Data da publicação: 20 maio 2011. Disponível em: <http://www.tjdft.jus.br/publicacoes/publicacoes-oficiais/ resolucoes-do-pleno/2011/00005.html>. Acesso em: 28 set. 2015.

ENTELMAN, Remo F. Teoría do conflito: hacia um nuevo paradigma. Barcelona: Ed. Gedisa, 2002.

FISS, Owen. Um novo processo civil: estudos norte-americanos sobre jurisdição, constituição e sociedade. São Paulo: Revista dos Tribunais, 2004.

LOVE, Lela P.; KOVACK K. Kimberlee. Mapeando a mediação: os riscos do gráfico de Riskin. In: AZEVEDO, André Gomma (Org.). Estudos em arbitragem, mediação e negociação. Brasília: Brasília Jurídica, 2004. Vol. 4.

MARTINS FILHO, Ives Gandra da Silva. Evolução histórica da estrutura judiciária brasileira. Revista Juridica Virtual, Brasília: Presidência da República; Casa Civil; Subchefia para Assuntos Jurídicos, v. 1, n. 5, set. 1999. Disponível em: <http://www.planalto.gov.br/ ccivil_03/revista/Rev_05/evol_historica.htm>. Acesso em: 14 jun. 2014.

MCGILLIS, D. Community Mediation Programs: Developments and Challenges, Washington D.C.: Diane Publishing, 1997.

MOORE, Christopher W. O processo de mediação: estratégias práticas para a resolução de conflitos. 2. ed. Porto Alegre: Artmed, 1998.

MUSZKAT, Malvina Ester. Guia prático de mediação de conflitos: em família e organizaçóes. São Paulo: Summus, 2005. 
RISKIN, Leonard. Compreendendo as orientaçóes, estratégias e técnicas do mediador: um padrão para perplexos. In: AZEVEDO, André Gomma (Org.). Estudos em arbitragem, mediação e negociação. Brasília: Brasília Jurídica, 2002.

SALES, Lília Maia de Morais. Justiça e mediação de conflitos. Belo Horizonte: Del Rey, 2003.

SANTOS, Boaventura de Sousa. $O$ discurso e o poder: ensaio sobre a sociologia da retórica jurídica. Porto Alegre: Sérgio Antonio Fabris Editor, 1988.

SCHMITZ, Suzanne J. O que deveríamos ensinar em cursos de Rad? Conceitos e habilidades para advogados que representam clientes em processos de mediação. In: AZEVEDO, André Gomma de. Estudos em arbitragem, mediação e negociação. Brasília: Grupos de Pesquisa, 2003. p. 89-108. Vol. 2.

SERPA, Maria de Nazareth. Mediação, processo judicioso de resolução de conflitos. Belo Horizonte: Faculdade de Direito da UFMG, 1997.

SIX, J. F. Dinâmica da mediaçâo. Belo Horizonte: Del Rey, 2001.

WARAT, Luis Alberto. Surfando na pororoca: ofício do mediador. Florianópolis: Fundação Boiteux, 2004.

Recebido em: 31/5/2016

Aceito em: 14/12/2016 